\title{
As Palavras Navegantes: a contribuição das linguagens virtuais na formação do adolescente contemporâneo
}

Iara Mara Moreira Martins*

Resumo: Este artigo trata da contribuição das linguagens virtuais na formação social dos adolescentes contemporâneos e consequentemente da sua presença enquanto novas formas de apreensão do conhecimento. As gerações atuais adquiriram novas percepções, advindas pela agilidade com que captam a realidade concreta através do mundo virtual. A fluidez das informações e a possibilidade de acesso a todo conhecimento humano presentes na Internet trouxeram novos componentes para a formação e desenvolvimento de sujeitos que se encontram na fase da adolescência. O espaço geográfico transformou-se em um imenso campo virtualizado, codificado, onde o adolescente realiza sua leitura do mundo a partir de múltiplas ferramentas como a imagem, o símbolo, traduzindo em linguagem escrita e oral. Há especificidades que o singularizam enquanto ser em desenvolvimento: todo o conhecimento encontra-se à disposição na Internet, não há assuntos proibidos ou censurados nem ao menos limite de tempo para o acesso. Ao mesmo tempo em que o recurso virtual visa ao lazer, coexiste a aquisição de valores que irão compor sua formação como sujeito social. No ambiente virtual as linguagens representam para o adolescente o desenvolvimento de habilidades e a ampliação de suas capacidades, em uma ação transformadora $e m-s i$, para-si que resultam em novas

* Assistente Social graduada pela Faculdade de Serviço Social da PUCRS, Mestre em Serviço Social pelo Programa de Pós-Graduação em Serviço Social PUCRS. E-mail: iaramaramm@yahoo.com.br. 
formas de aprendizado com protagonismo e autonomia na busca de conhecimento e expressão social.

Palavras-chave: Linguagens virtuais; Adolescente; formação social.

Resumen: Este artículo describe la contribución de los contemporáneos de adolescentes de idiomas virtual de formación social $\mathrm{y}$, en consecuencia, su presencia mientras nuevas formas de toma de conocimiento. Las generaciones actuales han adquirido nuevas percepciones, llegando con agilidad que captura la realidad a través del mundo virtual. El libre flujo de información y la posibilidad de acceso a todo el conocimiento humano presente en la internet traído nuevos componentes para la formación y desarrollo de temas que están en la etapa de la adolescencia. El espacio geográfico se convirtió en un enorme campo virtualizado, donde se realiza el adolescente codificado su lectura del mundo desde múltiples herramientas tales como imagen, símbolo, traducción escrita y lenguaje oral. Hay detalles que hacen mientras bajo desarrollo: todo el conocimiento está disponible en internet, allí no hay temas prohibidos o censurados o al menos tiempo límite para el acceso. Mientras el recurso virtual destinada al ocio, convive la adquisición de valores que componen el su formación como sujeto social. En el entorno virtual para los idiomas representan el desarrollo de habilidades adolescentes y expansión de su capacidad de fabricación, en un acción en-si,-si resultan en nuevas formas de aprendizaje con papel y autonomía en la búsqueda de conocimiento y expresión social.

Palabras clave: Idiomas virtuales; Adolescente; Formación social. 


\section{As palavras contemporâneas agora navegam: o discurso virtual como formador social do adolescente}

O interesse pela linguagem enquanto profissional do Serviço Social decorreu durante a elaboração de um projeto de intervenção com adolescentes na perspectiva dos Direitos Humanos, em uma instituição municipal de Porto Alegre ${ }^{1}$, nos anos de 2008 a 2009. Esse direcionamento acrescido à percepção de que o cotidiano dos adolescentes era atravessado por diversas linguagens motivou-nos a iniciar uma pesquisa em nível de mestrado ${ }^{2}$ a fim de compreender os sentidos e os significados que estes atribuem às linguagens que utilizam. Para tanto se optou por delimitar o foco para as linguagens virtuais, com as quais os adolescentes tem reconhecidamente ampla identificação.

É preciso distinguir linguagem de língua, que segundo Coseriu, "falar é sempre falar uma língua, não uma linguagem", já a linguagem é um fato social que a língua se impõe aos falantes (COSERIU, 1977, p. 32). Coseriu nos diz que o ser humano vive em um mundo linguístico que ele mesmo cria como ser histórico.

Segundo o Dicionário Larousse, a palavra língua significa um "sistema vocais e/ou gráficos, próprios de uma comunidade de indivíduos", utilizada como instrumento de comunicação ou expressão", e linguagem significa a "capacidade dos seres humanos de exprimir seu pensamento e de comunicá-lo por meio da língua” (LAROUSSE, 1999, p. 571).

Para Almeida (2001, p. 294), a linguagem é "indispensável para a construção da cultura, esse conjunto de tradições,

I O trabalho socioeducativo realizado na perspectiva dos Direitos Humanos consistiuse em incluir as linguagens mais utilizadas pelos adolescentes em seu cotidiano, tais como as linguagens da pichação, vestimentas, dos celulares e virtuais. Dentro dos sentidos e significados que cada linguagem continha para sujeito, construiu-se um espaço de reflexão sobre escolhas e valores.

2 Referência à dissertação de mestrado em Serviço Social, submetida em 21/12/2011, PUCRS, intitulada “' $\mathrm{O}$ sentido das linguagens virtuais na formação do sujeito social”, a qual serviu de base para o presente artigo. 
valores e significados transmitidos de geração em geração". Ou seja, a linguagem encontra-se presente na formação e evolução da própria condição humana, contendo em si, possibilidades de tradução das mudanças nos processos sociais.

Sendo assim, refletimos: O que a linguagem tem a ver com a formação e desenvolvimento social dos sujeitos? Tudo. Desde os tempos pré-históricos a necessidade de interação na luta pela sobrevivência levou os seres humanos à formação de grupos para a divisão de tarefas. Era necessário transmitir como e o que se pretendia executar. Com isso, surgem os gestos, as pinturas nas cavernas que antecedem o uso dos símbolos e o surgimento rudimentar da escrita, e o som que antecede a música e a fala.

A linguagem reproduz a realidade. Isso deve entender-se da maneira mais literal: a realidade é produzida novamente por intermédio da linguagem. Aquele que fala faz renascer pelo seu discurso o acontecimento reproduzido. Assim a situação inerente ao exercício da linguagem, que é a da troca e do diálogo, confere ao ato de discurso dupla função: para o locutor, representa a realidade; para o ouvinte, recria a realidade. Isso faz da linguagem o próprio instrumento da comunicação intersubjetiva (BENVENISTE, 1991, p. 26).

As linguagens que denominamos adolescentes encontramse presentes na urgência das mensagens nos celulares, nos fóruns de debates em comunidades, a ampliação de relacionamento nas redes sociais, trazendo para sua vida outras novas realidades. A linguagem adolescente é cifrada e está presente nos muros da cidade, nas conversas virtuais, em sua oralidade, vestimentas e gestuais. O cotidiano do adolescente está definitivamente imbricado à influência do virtual nas relações sociais. Como traduzir então a fala desse sujeito quando ele circula com igual desenvoltura entre a realidade concreta e a virtual, sintonizado com as constantes mudanças tecnológicas?

Mas, de repente, os saberes começam a pulular fora dos limites oficiais do saber definidos pela escola tradicional. Circulam livres no ar, sem depender de turmas, salas, aulas, programas, professores, livros-texto, dotados do poder divino de onipresença: o "aprendiz" aperta um botão e viaja instantaneamente pelo espaço. O "aprendiz" se descobre 
diante de um mundo imenso onde não há caminhos pré-determinados por autoridades exteriores. É o seu desejo que dá as ordens (ALVES, 2005, p. 121).

Um celular hoje está além de ser um aparelho feito para falar e ouvir alguém, nele pode-se comunicar usando imagens, textos, símbolos, escutando, recebendo e enviando músicas. Tudo ao mesmo tempo, conectado na rede mundial de computadores. Esse é somente um dos aspectos que os adolescentes contam em sua formação, que o torna um sujeito singular, capaz de alcançar dimensôes além do território ao qual pertence, inter-relacionando saberes atemporais em tempo real.

Adolescentes são sujeitos naturalmente abertos ao novo, afeitos a ampliar suas capacidades para a obtenção de informações que os levem a novos conhecimentos e contatos relacionais. A navegação no ambiente virtual da Internet faz desse sujeito um ser que desenvolve suas habilidades conjuntamente com novas tecnologias. A rapidez, a fluidez das informações dispostas no meio virtual passa a serem características absorvidas que ele exercita na facilidade com que fala com várias pessoas ao mesmo tempo online e desempenha outras ações ao mesmo tempo. Nascido em um mundo onde as informaçôes se apresentam fragmentadas no dia a dia, ele elabora suas relações à distância e tem uma escrita também fragmentada. Resta-nos saber se (e qual é) a dimensão em que a fragmentação presente em sua linguagem atinge sua formação como sujeito social.

A vida do adolescente é marcada pelo entrelaçamento do cotidiano com o virtual, ele não teme o erro na tentativa de execução dos comandos que o levarão a sites nunca antes navegados. Pelo contrário, a característica virtual de sempre apresentar um novo componente (ou comando) que levará a novos caminhos é uma constante para o adolescente no universo virtual. Ele se torna um sujeito construto de suas habilidades. Esse fato por si nos dá pistas de que algo diferenciado habita a formação desses sujeitos, e que, portanto, a escola, a família e a sociedade como 
um todo precisam olhar com atenção esse adolescente contemporâneo, a fim de dimensionar os sentidos que as linguagens virtuais representam para ele.

\section{Discurso, linguagem e ideologia: formação discursiva e ideológica}

Toda linguagem compartilha algo com alguém, da mesma forma a fala do sujeito compartilha visôes de mundo. Sendo um ser essencialmente relacional, é no meio social que ele vai abastecer as ideias, estas passam a ser representações que ele irá supor serem suas para compor sua compreensão da vida, e as irá expressar através do discurso construído.

A palavra é o signo ideológico por excelência; ela registra as menores variações das relações sociais, mas isso não vale somente para os sistemas ideológicos constituídos, já que a "ideologia do cotidiano", que se exprime na vida corrente, é o cadinho onde se formam e se renovam as ideologias constituídas. Se a língua é determinada pela ideologia, a consciência, portanto o pensamento, a "atividade mental", que são condicionados pela linguagem, são modelados pela ideologia. Contudo, todas estas relações são inter-relações recíprocas, orientadas, é verdade, mas sem excluir uma contra-ação (BAKHTIN, 1992, p. 16).

Ao valorizarmos os sentidos que as linguagens virtuais possuem para o adolescente contemporâneo, faz-se necessário o estudo das suas formações discursivas e a formações ideológicas presentes na linguagem. Segundo Fiorin (1993), formaçôes discursivas são "conjunto de temas e de figuras que materializa uma dada visão de mundo", elas estão presentes no discurso que o sujeito constrói a partir das formações ideológicas. Portanto, estas pertencem a uma ordem mais ampla que a formação discursiva, trata-se de uma "visão de mundo de uma determinada classe social, $[. .$.$] um conjunto de representações, de ideias que revelam a$ compreensão que uma dada classe tem do mundo" (idem, p. 32). Sendo assim, o sujeito tem em sua linguagem uma construção discursiva que se dá em um âmbito social, que o envolve. 
É com essa formação discursiva assimilada que o homem constrói seus discursos, que ele reage linguisticamente aos acontecimentos. Por isso, o discurso é mais o lugar da reprodução que o da criação. Assim como uma formação ideológica impõe o que pensar, uma formação discursiva determina o que dizer. Há, na formação social, tantas formações discursivas quantas forem as formações ideológicas (FIORIN, 1993, p. 32).

O discurso dominante é o que determina os rumos da sociedade, impõe sua lógica, estabelece parâmetros daquilo que efetivamente é aceito por suas estruturas sociais de poder. Ele não é único, existem demais formações ideológicas em confronto e, dessa forma, ainda que a formação discursiva a ela esteja submetida, a consciência individual atua através da linguagem no campo social organizado a partir do "nós". Nesse sentido, o grupo atua tanto como unidade reiterando valores apreendidos, bem como unidade dissonante da ordem instituída, expressando através de linguagens alternativas seu posicionamento contrário.

A nova realidade econômica é cada vez mais sensível a atributos educativos como visão de conjunto, autonomia, iniciativa, capacidade de resolver problemas, flexibilidade. Formação básica torna-se mais estratégica que especialização profissional, já que o processo produtivo tem sua qualidade e competitividade condicionadas à capacidade de organização processual, prevenção de falhas, incremento qualitativo de processos e etapas, reinterpretação de situações, exigindo raciocínio analítico, habilidade e rapidez para processar informação e tomar decisões (DEMO, 1993, p. 24).

O sujeito intui o processo de subjugação ao qual está exposto, em diferentes níveis de compreensão crítica dos mecanismos ideológicos ele busca alternativas que o levem à resistência. Muitas vezes ele usa do próprio mecanismo ideológico para produzir sua denúncia, ainda que inócua, ele declara para a sociedade que está ciente do processo de dominação a que está exposto. De acordo com Foucault (1999, p. 11-2), são nos saberes sujeitados que se encontra a força do saber das pessoas, saberes compostos de duas formas de saberes, os saberes construídos pela erudição e os saberes hierarquicamente inferiores. É o acoplamento desses dois saberes que "permite a constituição de um saber das lutas" (FOUCAULT, 1999, p. 13). 
$\mathrm{Na}$ visão foucaultiana, "trata-se de uma insurreição dos saberes". Dessa forma, a leitura de mundo adolescente, a construção do que entende por realidade, sociedade, por relaçôes sociais e por si mesmo, passam hoje pelos meios virtuais. As redes em que estabelece relacionamentos, nas conexões que realiza ele vai construindo seu entendimento de sociedade. Se, conforme Bakhtin, "a palavra é o fenômeno ideológico por excelência [...] o modo mais puro e sensível de relação social, [...] o material privilegiado da comunicação na vida cotidiana" (1992, p. 37), hoje vemos a palavra definitivamente virtualizada. Ela atinge contemporaneamente novas dimensões ainda a serem devidamente elucidadas, pois a nova ordem pautada pelo predomínio das relações virtuais vem afetando a formação desse sujeito. Ele traduz a partir de mecanismos virtuais de expressão e relacionamento ainda sem a devida compreensão do que este meio representa para sua formação social e ideológica.

Nesse processo, a ideologia e a linguagem como principais expressões de uma nova cultura colocam-se como eixos centrais. [...] [a linguagem] como veículo de expressão e socialização da nova concepção de mundo, demonstra o maior ou menor grau de complexidade desta e seu potencial na construção da nova unidade sociocultural fundada em novos códigos de sociabilidade (ABREU, 2002, p. 135-36).

Vemos no presente momento histórico um sujeito que se encontra muitas vezes a reproduzir linguagens virtuais no intuito de estar inserido socialmente. A sua busca pelo protagonismo nas pequenas decisões diárias que empreende no uso das ferramentas virtuais representa mais que a vontade de estar dentro de um grupo, significa também um preparo para a vida adulta. É provável que nem todo sujeito adolescente tenha a dimensão ampla do que venha a representar essa trajetória para sua formação. Entretanto, visto que nenhum processo de formação social pode ocorrer sem a percepção si e do outro, se presume que o meio social atue indistintamente nas relações virtuais baseadas nas linguagens ali praticadas. 
A linguagem tem influencia também sobre os comportamentos do homem. O discurso transmitido contém em si, como parte da visão de mundo que veicula um sistema de valores, isto é, estereótipos dos comportamentos humanos que são valorizados positiva ou negativamente. Ele veicula os tabus comportamentais. A sociedade transmite aos indivíduos - com a linguagem e graças a ela - certos estereótipos, que determinam certos comportamentos. Esses estereótipos entranham-se de tal modo na consciência que acabam por ser considerados naturais. (...) Não devemos esquecer que os estereótipos só estão na linguagem porque representam a condensação de uma prática social (FIORIN, 1993, p. 55).

É preciso entender o adolescente como um ser relacional que não está destacado de todos os processos de despersonalização dos sujeitos, em meio ao adensamento da divisão de classes, para que ele compreenda e tenha uma posição crítica dos processos de desigualdade social. Contudo, a consciência desses mecanismos ideológicos não poderá se dar solitária, é preciso que ele compreenda sua relação com o mundo.

Esta relação existe em toda a sociedade no seu conjunto e em todo indivíduo com relação aos outros indivíduos, bem como entre camadas intelectuais e não intelectuais, entre governantes e governados (...). Toda relação de "hegemonia" é necessariamente uma relação pedagógica, que se verifica não apenas no interior de uma nação, entre as diversas forças que a compõem, mas em todo campo internacional e mundial, entre conjuntos de civilizações nacionais e continentais (GRAMSCI, 1995, p. 37).

Não há fronteiras para elaborar essa realidade, o concreto sofre interferência das relações estabelecidas virtualmente. Ele não dependerá unicamente de sua trajetória construída individualmente, construídas através de suas ações na sociedade, pois passa a contar com conceitos ampliados de espaço, território. Ele está presente em muitos espaços ao mesmo tempo e determinando novas concepçôes de sujeito e de sociedade.

A forma de apreensão depende do sujeito cognoscente, isto é, do gênero de prática, acumulada na filogênese e na ontogênese, de que dispõe. É por isso que uma mesma realidade pode ser apreendida diversamente por homens distintos. A consciência humana depende, pois, da linguagem 
assimilada. Não só os elementos semânticos, diretamente determinados pelas formações ideológicas, mas também as categorias linguísticas que gozam de uma certa autonomia em relação às formações sociais exercem um papel ativo na percepção do mundo (FIORIN, 1993, p. 54).

Dessa forma, quando se pensa em linguagem, enquanto formação ideológica, e consequentemente discursiva, é extremamente necessário deixarmos a lado conceitos duais de certo ou errado. Há que se questionar a existência de formações ideológicas atendendo a interesses específicos na vida do adolescente. Sabemos que é algo inevitável, porém pensa-se que fomentar um diálogo aberto com o adolescente contribui positivamente para que ele reelabore sua posição como sujeito social.

A partir de determinada linguagem utilizada pelo sujeito, lembrando que a dimensão em que este estudo perscruta circula pela formação social do ser, resta-nos investigar nesta esfera todos os aspectos. Há sentidos pertinentes para, por exemplo, o adolescente que pratica pichações, pois ele busca marcar sua presença nos muros da cidade da mesma forma que posta mensagens nas comunidades virtuais. O que sua marca ("tags") representa para ele circulando entre essas dimensões (real/virtual)? O que ele está querendo nos dizer, enquanto unicamente manifestação do símbolo linguístico que o identifica?

Toda refração ideológica do ser em processo de formação, seja qual for a natureza de seu material significante, é acompanbada de uma refração ideológica verbal, como fenômeno obrigatoriamente concomitante. A palavra está presente em todos os atos de compreensão e em todos os atos de interpretação (BAKHTIN, 1992, p. 38).

Sendo assim, os aspectos simbólicos ${ }^{3}$ e ideológicos das linguagens virtuais adolescentes são conceitos significativos para compreender e analisar os sentidos que se encontram nas formas de expressão e comunicação virtuais. Representa um grande desafio compreender o quanto essas linguagens atuais contribuem

3 Simbólico: tudo o que é produzido pela mente humana para representar realidades que estão além do mundo material, concreto. Neste sentido, a própria linguagem é simbólica. Assim também a cultural (CABRAL, 1999, p. 388). 
para a formação do sujeito em sua sociabilidade como ser com valores éticos.

Hoje, o adolescente não é mais um sujeito que se encontra em estado passivo na obtenção de conhecimento. Ele já se encontra sujeito de sua própria história, porém sua pouca trajetória de vida requer a contribuição de uma base sólida ética para que ele se torne capaz de enfrentar os processos ideológicos de dominação e subsunção ${ }^{4}$ perpetrados na sociedade.

\section{As Linguagens Virtuais e o adolescente: a vida passa pela rede}

O universo adolescente adquire movimentos peculiares, presentes em seu modo de vestir, falar, escrever, relacionar-se e de comunicação com o tecido social. Cada uma dessas formas de expressão e comunicação, aspectos vistos isoladamente, deixa de ser visualizado como linguagens que os caracteriza e os singulariza; para que vejamos neles seus sentidos enquanto linguagens precisar-se-á apreendê-los em seu conjunto. É necessário estabelecerem-se nas linguagens adolescentes conexões com a realidade mais ampla, ou seja:

[...] dialética da realidade social é o ponto de vista da totalidade concreta, que antes de tudo significa que cada fenômeno pode ser compreendido como momento do todo. Um fenômeno social é um fato histórico na medida em que é examinado como momento de um determinado todo; desempenha, portanto, uma função dupla, a única capaz de dele fazer efetivamente um fato histórico: de um lado, definir a si mesmo, e de outro, definir o todo; ser ao mesmo tempo produtor e produto; ser revelador e ao mesmo tempo determinado; ser revelador e ao mesmo tempo decifrar a si mesmo; conquistar o próprio significado autêntico e ao mesmo tempo conferir um sentido a algo mais (KOSIK, 2002, p. 49).

4 Subsunção: do latim sumpcione, ação de tomar. Subsumir: sumere, acolher, tomar, aceitar. Na filosofia escolástica, relacionar, reportar um indivíduo a uma espécie; relacionar uma espécie a um gênero (Dic. Larousse Cultural, 1999, p. 845). 
Dessa forma, toda e qualquer manifestação social do adolescente encontra seu espaço no meio virtual comportando um sentido a ser desvelado. A realidade em permanente mutação é potencializada pelos constantes avanços dos recursos tecnológicos à disposição no meio virtual, fazendo com que os conceitos de tempo, território e de sociabilidade sejam igualmente ressignificados.

Esta recíproca conexão e mediação da parte e do todo significam a um só tempo: os fatos isolados são abstrações, são momentos artificiosamente separados do todo, os quais só quando inseridos no todo correspondente adquirem verdade e concreticidade. Do mesmo modo, o todo de que não foram diferenciados e determinados os momentos é um todo abstrato e vazio (KOSIK, 2002, p. 49).

Estar presente no mundo contemporâneo pode significar tanto para um sujeito que imprime clandestinamente sua marca ("tags") pelos muros da cidade e está inserido na Internet em comunidades e fóruns virtuais, relacionando-se com outros sujeitos que também se identificam com essa linguagem; participar de redes sociais MSN (Messenger), Facebook e outras, percorrendo ao mesmo tempo diferentes espaços, com a volatilidade da ação, relegando ao plano do abstrato o pertencimento, a inclusão e o exercício do afeto. Abaixo abordaremos brevemente as particularidades de algumas redes sociais mais reconhecidas pelos adolescentes,

\section{Orkut}

O Orkut é uma das primeiras redes sociais a serem utilizadas popularmente, criada em janeiro de 2004, recebendo o nome de seu criador, um funcionário da empresa Google, que se chama Orkut Büyükkökten. O seu objetivo inicial era facilitar aos funcionários da empresa conhecerem pessoas e construírem relacionamentos no meio virtual. Logo expandida aos demais usuários da rede mundial, tinha foco no público norte-americano, 
porém não houve grande interesse. Inicialmente, para entrar no Orkut era preciso receber convite de um usuário, atualmente qualquer pessoa pode fazer seu cadastro pessoal. Em 2005, devido ao grande número de usuários no Brasil (é o segundo país a nível mundial em acesso, perdendo apenas para a India) e o crescimento de solicitações legais em relação ao uso impróprio no país determinou que o Google, empresa norte-americana, instalasse uma filial brasileira do Orkut. Em 2008, a crescente utilização dos brasileiros faz com que o Google Brasil passasse a ter controle mundial do Orkut, dividindo responsabilidade com a Índia. Em abril de 2010, o Brasil tinha 48\% de usuários no ranking mundial ${ }^{5}$; a Índia 39,2\%; Estados Unidos 2,2\%; Japão 2,1\%; Paquistão $1,0 \%$ e demais países somavam 5,3\%.

Atualmente, o acesso ao Orkut vem diminuindo gradativamente, perdendo para o Facebook e Twitter, porém, existe um público brasileiro ainda fiel a essa rede social, acredita-se devido aos vínculos estabelecidos nas comunidades e relacionamentos iniciados nesse meio virtual. Talvez um dos grandes atrativos do Orkut que merecem atenção são justamente as comunidades, espaços onde se fomenta a discussão de temas variados, com postagem de links relacionados. Nas comunidades o usuário participa debatendo, recebendo ou alimentando a comunidade com novas informações sobre o assunto.

Os principais problemas da rede social Orkut são questões de privacidade, tais como roubo de senha e nome de usuário para uso indevido, perfis fakes (falsos) que podem ter utilização indevida; falhas na segurança, sujeito às exposições da atuação de hackers no roubo de informações dos usuários através de scraps ${ }^{6}$ contendo vírus; a utilização da rede para temas como racismo, combinação de confronto entre gangues e exposição indevida

5 Orkut.com - site infofromAlexa - www.alexa.com. Disponível em: < http:// pt.wikipedia.org/wiki/Orkut\#O_sistema>. Acesso em: 10 de dez. 2011.

6 Scrap em inglês significa "sucata, lixo". Em meio virtual significa pequenos textos inseridos na internet, "um tipo de recado virtual utilizado apenas na rede social Orkut” Disponível em: <http://pt.wikipedia.org/wiki/Scrap>. Acesso em: 10 de dez. 2011. 
das imagens infantis. São problemas pontuais a que a empresa Google disponibilizou uma tecla de acesso a qual o usuário, uma vez identificado algum conteúdo considerado inapropriado, possa vir a denunciar, para que a empresa Google possa identificar irregularidades.

\section{Facebook}

É uma rede social criada em fevereiro de 2004, por Mark Zuckerberg, Dustin Moskovitz, Eduardo Saverin e Chris Hughes, ex-estudantes da Universidade de Harvard. No início, somente estudantes dessa Universidade podiam participar, gradualmente foi sendo permitida a participação de estudantes de outras instituições estudantis norte-americanas, como o renomado MIT (Instituto de Tecnologia de Massachusetts) e a Universidade de Boston. $\mathrm{O}$ foco era construir uma rede de relacionamentos direcionada a estudantes, entretanto em setembro de $2005^{7}$ foi estendida a participação para estudantes do ensino médio norte-americano.

Logo, o Facebook tornou-se popularizado, sendo hoje a rede social de maior acesso em nível mundial, com alcance global de $38,1 \%^{8}$. O lema que se encontra na página de entrada é $O$ Facebook permite-te comunicar e partilhar com as pessoas que fazem parte da tua vida.

O Facebook é um site gratuito, mas que gera uma receita proveniente das propagandas e patrocínios que veicula ao lado dos perfis dos usuários. No momento em que o usuário está navegando no site, ele pode interagir com a propaganda veiculada, marcando como preferida ou mesmo indicando para amigos, as preferências e gostos dos usuários ficam visíveis para os demais amigos, servindo também de propaganda para as empresas

\footnotetext{
7 http://pt.wikipedia.org/wiki/Facebook. Acesso em: 10 dez. 2011.

8 Conforme Ad Planner Top 1000 Sites - junho/2010. Disponível em: <http:// pt.wikipedia.org/wiki/Facebook>. Acesso em: $10 \mathrm{dez} .2011$.
} 
patrocinadoras. O Facebook oferece ao usuário ferramentas para postar fotos que serão partilhadas com amigos, lista de interesses pessoais para divulgação de áreas profissionais e de afinidade, a possibilidade de troca de mensagens e postagens pessoais e privadas de fotos, vídeos e links. A visualização das informações poderão se dar de forma individual ou por grupos de interesse comum; possui diversos aplicativos (jogos interativos) que dispóem de atalhos e recursos que avisam os comandos dados pela outra pessoa, sem que se precise jogar em tempo real. $\mathrm{O}$ Facebook lista nomes de pessoas que estão presentes no grupo de amigos em comum, como possibilidade de novos contatos, como uma indicação de amizade.

A todas essas situações corriqueiras e conhecidas para o adolescente podemos chamar de linguagens, as formas de comunicabilidade e socialização em um território globalizado. A multiplicidade de símbolos atribui tantos significados quantos forem possíveis as traduções para aquilo que o adolescente e seu grupo pensam, deseja e quer conhecer.

O grande potencial para investimento do Facebook tornou essa rede social muito lucrativa para o mercado, potencializada por seu visual jovem e moderno. As imagens voltadas para propagandas nas abas e a possibilidade de o usuário comentar e mesmo recomendar produtos fez com que em 2007 a rede criasse a FacebookPlataform, para o desenvolvimento de aplicações a serem usadas no site ${ }^{9}$. Em agosto de 2011, foram contabilizados mais de 180 milhões de usuários ativos, 50 milhões de conteúdo compartilhado, com uma média de 135 amigos por usuário. O ranking de países, pela ordem de usuários: Estados Unidos, Reino Unido, Índia, Turquia, França, Itália, Canadá, Filipinas, Espanha, México e Brasil ${ }^{10}$.

9 Conforme Facebook's plan to hook up the world.
10 http://pt.wikipedia.org/wiki/Facebook. Acesso em: 10 dez. 2011. 


\section{Twitter}

O Twitter ${ }^{11}$ é uma rede social criada em 2006 por Jack Dorsey ${ }^{12}$ que conecta seus usuários em tempo real através da informação de ações postadas com até 140 caracteres, chamadas de "Tweets", pela rede definida como "pequenas explosões de informação" "13. Dessa forma, vê-se a força dos pequenos enunciados assumindo a principal característica de uma rede social. De acordo com BUZZI (1990, p. 237), "nos enunciados simples, nas declarações complexas e nos solenes relatos há um comando, uma prescrição, uma recomendação, um pedido, uma solicitação, uma súplica... Há o empenho de sentir a realidade".

A proposta do Twitter é de que o usuário possa "contar sua história no seu tweet", ou possa pensar em "um tweet como um título", ou ainda "usar o painel de detalhes para contar o resto com fotos, vídeos e outros conteúdos de mídia". Da mesma forma que o usuário "tweeta" sobre seu cotidiano, e é visto pelos demais usuários na qualidade de seus "seguidores", também ele pode "seguir" seus amigos, personalidades, empresas e instituiçóes.

$\mathrm{O}$ Twitter mantém um site ${ }^{14}$ em que divulga ações em defesa de causas sociais em nível mundial, podendo o usuário interagir na troca de informaçốes. A sede fica em São Francisco, Estados Unidos, está disponível para usuários de diversos países do mundo e oferece tradução do site para o inglês, francês, alemão, italiano, turco, japonês, coreano, filipino, espanhol e português.

Assim como o Facebook prevê ações que incluem a participação de empresas através do patrocínio e divulgação nas laterais da tela, o Twitter oferece a interação verbal entre empresa e clientes em tempo real no compartilhamento e obtenção de informações acerca de seus produtos e serviços. Dessa forma, as empresas, podem, através do Twitter, qualificar seus serviços ao

\footnotetext{
11 http://twitter.com. Acesso em: 10 dez. 2011.

12 http://pt.wikipedia.org/wiki/Twitter. Acesso em: 10 dez. 2011.

13 http://twitter.com/about. Acesso em: 10 dez. 2011.

14 www.hopel40.org. Acesso em: 10 dez. 2011.
} 
mesmo tempo em que fornecem dados e retira impressões dos clientes. Esses passam a interagir virtualmente influindo sobre as ações e o direcionamento dos negócios da empresa.

Relacionam-se duas características significativas do Twitter que o distingue das demais redes sociais e que são novas nas relações sociais em meio virtual: a primeira é a possibilidade do usuário de, como "seguidor", obter informações "tweetadas" diretamente de personalidades com as quais ele se identifica ou então as idealiza. Existe a palavra autoral do sujeito-personalidade, a fomentar de informações pessoais o ideário de seu público, agora na qualidade de "seguidores".

A segunda característica, extremamente significativa, é seu principal recurso em si, que na definição do próprio Twitter, representam "pequenas explosões de informação", pois convida o usuário a desenvolver uma habilidade de exercer com criatividade a capacidade de visualizar a totalidade sobre seu cotidiano: o poder de síntese.

Porém não se configura tarefa fácil desenvolver essa habilidade, traduzir em poucas palavras o que é mais relevante, apresentar para outrem aquilo que somente a si faz sentido. Quando o sujeito "tweeta" ele coloca cores em suas pequenas sentenças com uma intenção pessoal, ele apresenta de forma minimalista no meio virtual como ele sente e percebe o mundo que o cerca.

Na fala, nos tornamos dialogantes e criativos, semelhantes à linguagem (logos) que sempre e por toda parte nos incita à luta e à criação, ao comprometimento e à responsabilidade. Basta alguém abrir a boca e já estamos no bate-papo, discutindo, dialogando, persuadindo, convencendo, consentindo, dissentindo, comandando... Adoramos falar porque fazemos experiência de um imenso poder de criação. Um sentido latente, qual fogo que incendeia, anima as palavras como a vida anima os membros do corpo. Como merecer esse sentido? (BUZZI, 1990 , p. 237-238).

Mas há também um aspecto significativo: a linguagem em estado reduzido chega por vezes à sensação de que abrange o todo, de que tudo foi dito em poucas palavras, e talvez tenha sido para aquele que a proferiu. A sentença chega ao outro que 
a recebe dando-lhe novo sentido, atribuindo vários outros significados a ele pertinentes e talvez distintos da intenção daquele que a emitiu.

Não vivemos, pois, estupidamente no imediato das coisas, à maneira animal, sem qualquer sentido. Estamos no logos, isto é, no fogo da linguagem, que nos dá o poder de criar um mundo de símbolos, inacessível ao animal. Vivemos tudo no transpasse, na persuasão, no lance arriscado e na luta das palavras, nos dentros de sua sedução, na ardência de seu sentido (BUZZI, 1990, p. 238).

Reconhece-se a riqueza da linguagem nesse movimento. Entretanto, é preciso que os sujeitos não se atenham tão somente a essa preciosa capacidade de síntese da linguagem através dos recursos virtuais, sem que pratiquem concomitantemente o exercício das linguagens formais. Elas são as que preparam, na realidade, para o mundo abstrato e o pensamento com poder de síntese transformador.

Sem essa intercessão, o processo de formação da consciência crítica fica comprometido; dessa forma, um "tweeter" se reduz à mera informação do ato tão somente, pois a ação "tweetar" desenvolve o movimento do particular para o todo. Por essa razão, a existência do processo de formação social aprimora e qualifica aquilo que o sujeito irá postar. Provavelmente, o grande atrativo da rede social Twitter venha a ser essa linguagem instantânea, fluída, tão identificada com a urgência adolescente.

Dessa forma, poderíamos imaginar que, se fosse possível ao adolescente projetar uma tecla imaginária onde a agilidade das "pequenas explosões de informação" do Twitter pudesse ser incorporada nas demais comunicações fora do ambiente virtual, por exemplo, ele, por certo, o faria. Sendo assim, percebe-se que as reduções nos enunciados promovidos pelos meios virtuais trouxeram para o adolescente o desejo de imprimir em sua comunicação nas relações sociais a agilidade e a síntese na redução da linguagem vivenciada na virtualidade. 


\section{Messenger}

Em 1999, a Microsoft Corporation criou um programa de mensagens instantâneas denominada MSN Messenger ${ }^{15}$, que permite ao usuário conversar em tempo real com outros usuários simultaneamente. O MSN Messenger é o posterior ao programa $\mathrm{ICQ}^{16}$, pioneiro nesse tipo de comunicação, em 2006 é incorporado ao Windows Messenger, originando o Windows Live Messenger. Em 2009, está disponível em 36 idiomas, recebendo mais de 330 milhões de visitantes por mês.

Entre outras ações, o MSN disponibiliza ao usuário conversar com o auxílio de um webcam (vídeo), enviar os chamados emoticons, símbolos que expressam emoções, além da postagem de mensagens animadas, fotos e documentos. O usuário possui em seu perfil um campo, onde através de uma frase, cita autores ou mesmo posta sentimentos e impressóes do seu dia a dia, movimento semelhante ao que hoje é oferecido no Twitter. É possível visualizar quem entra e quem sai do MSN, como também ficar invisível, e a conexão com Facebook e MySpace ${ }^{17}$, tornando as ações possíveis de serem compartilhadas. O Windows Live Messenger oferece vários recursos como a possibilidade de se comunicar off-line, semelhante ao status visível com outra pessoa; deixar uma mensagem para um contato que está off-line; chamar um contato para conversa imitando o ruído de um telefone; as atualizaçôes dos usuários ficam visíveis para todos os contatos da lista. A partir de 2010, tornou-se disponível o acesso do Messenger no telefone celular. A versão 2011 do Messenger apresenta em seu painel social funções que a aproximam dos sites de rede social; é possível exportar dados das outras redes sociais.

\footnotetext{
15 http://pt.wikipedia.org/wiki/MSN_Messenger. Acesso em: 10 dez. 2011.

16 ICQ sigla do inglês I SeekYou (eu procuro você). O ICQ surgiu em 1996, é o primeiro programa de comunicação instantânea pela internet, sendo ainda utilizado em alguns países da Europa. http://pt.wikipedia.org/wiki/ICQ. Acesso em: 10 dez. 2011.

17 Site de música.
} 
Atualmente, todas as redes sociais disponibilizam o envio de mensagens instantâneas, porém o MSN ainda é o programa mais utilizado, geralmente de forma simultânea com as demais redes.

\section{Mensagens SMS - "torpedos"}

O Serviço de mensagens curtas (em inglês short message service $)^{18}$ mais conhecido como mensagens SMS ou popularmente chamado de torpedo, foi inventado por Matti Makkonenh, um engenheiro civil na década de 80 . O primeiro SMS foi enviado em 1993 de um computador pessoal para um telefone celular, no Reino Unido. O serviço de mensagens curtas foi criado originalmente para comunicações rápidas de texto através de celulares. Vê-se hoje que as mensagens SMS são serviços disponíveis nos aparelhos celulares que são amplamente utilizados pelos adolescentes, pois permitem o envio de mensagens de texto que podem ser digitadas pelo usuário ou pré-gravadas. Podem ser acrescentados às mensagens os recursos de símbolos (emoticons) e imagens.

Com o avanço tecnológico dessas ferramentas virtuais, existem atualmente no mercado aparelhos que oferecem o acesso à rede mundial de computadores (Internet) e a comunicação pode ser também on-line (em tempo real). Entretanto, acredita-se que pela rapidez e facilidade com que o usuário pode comunicar-se sem a conexão da Internet, a mensagem SMS é muito utilizada mesmo por quem possui celular com acesso à Internet no celular. As operadoras de telefonia vêm oferecendo pacotes de serviços, planos e promoçóes que proporcionam o uso prolongado ou mesmo ilimitado de mensagens SMS, tornando esse recurso virtual um dos mais utilizados por adolescentes de todas as classes sociais.

Essa é hoje uma questão polêmica, pois tem como pano de fundo o debate sobre o uso intermitente dos aparelhos celulares

18 http://pt.wikipedia.org/wiki/Servi\%C3\%A7o_de_mensagens_curtas. Acesso em: 10 dez. 2011. 
pelos adolescentes em diversos espaços sociais muitas vezes de forma inadequada. Acredita-se que o mau uso dos celulares pelos adolescentes estaria causando interferência na concentração das atividades didáticas e, consequentemente, na aprendizagem do aluno.

Em 03 de junho de 2009 a Comissão de Educação e Cultura aprovou em texto substitutivo ao Projeto de Lei 2246/07 de autoria do deputado Pompeo de Mattos $(\mathrm{PDT} / \mathrm{RS})^{19}$, a proibição do uso de celulares nas salas de aula do ensino básico de todo o país por alunos e professores. $\mathrm{O}$ texto original prevê a proibição para toda a rede pública de ensino. A relatora deputada Ângela Portela (PT/RR) declara que há o uso abusivo dos celulares, citando entre as ações praticadas estão "o troca-troca de torpedos, os jogos, as colas e as conversas ao telefone, mas há também menção a conteúdos relacionados com pornografia e violência". No Acre, a PL 2547/07 proíbe o uso de aparelhos eletrônicos portáteis sem fins educativos nos ensinos fundamental, médio e superior das escolas públicas do país.

Essa é uma realidade que precisa ser analisada e debatida em conjunto com os adolescentes em nível de valores, pois independentemente de se estabelecerem normas proibitivas para o uso dessa ferramenta virtual, a ação continuará sendo praticada.

\section{Adolescentes, sujeitos em desenvolvimento na virtualidade}

Antes de qualquer coisa é preciso definir o que representa ser adolescente. Da mesma forma que o conceito de criança como indivíduo em desenvolvimento que tem necessidades específicas de sua etapa evolutiva surge em torno do século XVIII, a adolescência é conceituada em torno do século XX (ARIÈS, 1981; POSTMAN, 1999 Apud OUTEIRAL, 2003, p. 103). É um

19 http://www.panoramabrasil.com.br/educacao-proibe-uso-de-celulares-em-escolasde-ensino-basico-id29328.html. Acesso em: 10 dez. 2011. 
período do desenvolvimento do ser humano marcado por intensas transformações, onde este se vê no limiar entre a infância e a proximidade do mundo adulto. É marcado por crises (do grego krisis, mudança) (CARVAJAL, p. 11) que correm paralelas com a descoberta de um contínuo desenvolvimento de si e frente à vida que o espera na expectativa de novas realidades.

O período de mudanças e crises chamado de adolescência é, sem dúvida, a mais turbulenta dessas fases. Abarca mais ou menos a segunda década da vida. [...] leva à maturação física e inclusive à possibilidade da sexualidade adulta, procriativa [...] o fenômeno da adolescência só é encontrado no desenvolvimento do ser humano (VILLARREAL, 2001, p. 11 $)^{20}$.

A palavra adolescer vem do latim adulescens ou adolesces e significa homem jovem, e como particípio ativo do termo adolescere significa crescer, se desdobrarmos a palavra encontramos mais outro significado "dolescere" ou "dolere", significa também doer (CARVAJAL, 2001, p. 21). Esses são os significados que encerram a palavra, e que dão uma noção de quão intensa é essa fase da vida do sujeito. Contudo, a intensidade com que $\mathrm{o}$ adolescente vive sua fase de vida não pode ser vista somente em seus aspectos doídos ou angustiantes. A densidade também se dá pela capacidade ali desabrochada de se aventurar rumo ao desconhecido, reconhecer em seu cotidiano os sentidos e os significados que encontram nas linguagens escolhidas.

Ser adolescente é antes de tudo estar aberto ao mundo de uma maneira formidável, como em nenhuma outra etapa da vida o sujeito experiencia. As tentativas e os erros não constituem motivos para que ele se imobilize, pelo contrário, ele busca a ação que o leva ao novo e desconhecido com uma impetuosidade que constrangem ao mundo adulto, por haverem esquecido há muito tempo essa capacidade espontânea de viver. A forma de ser do adolescente o abre para a vida de uma maneira abrupta, e nem sempre os adultos encontram-se receptivos ou prontos a compreender de forma a ampará-lo nessa caminhada.

20 VILARREAL, Inga. Prólogo, IN: CARVAJAL, 2001, p. 11. 
A curiosidade transbordante do adolescente, sua necessidade de ter certeza de tudo, seu animo de experimentar tudo sozinho, seu intenso oposicionismo, sua culpa inconsciente por ser rebelde, sua compulsão a ser absolutamente diferente, sua falta de experiência, sua ignorância dos perigos que $\mathrm{o}$ adulto conhece, e sua liberdade sem limites, expõem-no a um altíssimo risco imediato (CARVAJAL, 2001, p. 23).

A aparente ausência do medo em arriscar e prosseguir no curso de novas experiências frequentemente os coloca em situações com sérias consequências, tais como uma gravidez indesejada, dependência de substâncias psicoativas (drogas e álcool) entre outras. Esses fatores, de certa forma, contribuem para uma visão estereotipada do adolescente em que predomina a quebra da norma instituída e a tendência para o desvio social. As manifestações comportamentais de enfrentamento da autoridade, seja familiar ou social, passam a ser vistas como socialmente conflituosas. São extremamente difíceis para a família e os educadores, atores sociais mais próximos do adolescente, empreenderem um relacionamento contributivo nesse período tão intenso, quando situações aparentemente insignificantes aos adultos adquirem aspectos monstruosos. Ora envoltos nas observações espirituosas sobre tudo no cotidiano, ora extremamente críticos, são sujeitos que estão desenvolvendo uma arguta capacidade de ver a vida e pensar sobre ela.

Em ambos os sexos, o desenvolvimento intelectual também é notável, com o surgimento do raciocínio hipotético-dedutivo, permitindo generalizações mais rápidas, bem como compreensão de conceitos abstratos. Em decorrência, a independência intelectual surge com força, muitas vezes apresentando-se como rebeldia em relação às autoridades em geral. Este fato está ligado a essa recém-adquirida capacidade de abstração, reflexão e generalização a partir de hipóteses. Essa nova habilidade leva os jovens a uma abordagem mais filosófica e independente sobre quaisquer conceitos que lhes sejam apresentados (ZAGURY, 1996, p. 26).

Antes, na infância, o que lhe era dito pelas pessoas mais próximas a ele - pais e professores - era absorvido como verdade incontestável, na adolescência passa a ser alvo de questionamentos e de reflexão crítica. Os valores sociais passam então a ser 
igualmente avaliados pelo jovem, que vê a necessidade de buscar novas vias, outros rumos para percorrer.

O adolescente moderno aprende valores, virtudes que deve respeitar, mas vive num mundo adulto que os nega. Prega-se o amor, mas ninguém sabe em que ele consiste porque não se veem as açóes que o constituem, e se olha para ele como a expressão de um sentir. Ensina-se a desejar a justiça, mas os adultos vivem na falsidade. A tragédia dos adolescentes é que começam a viver um mundo que nega os valores que lhes foram ensinados. O amor não é um sentimento, é um domínio de ações nas quais o outro é constituído como um legítimo outro na convivência. A justiça não é um valor transcendente ou um sentimento de legitimidade: é um domínio de ações no qual não se usa a mentira para justificar as próprias ações ou as do outro (MATURANA, 1998, p. 33).

Adolescer em um mundo contraditório passa a ser uma experiência de uma dúvida constante, acrescido a essa fase de vida de um questionar de si e do outro, nesse sentido a atitude de rebeldia do adolescente se justifica. Somos seres que se encontram em processo de humanização, no nosso dia a dia vamos construindo coletivamente esse ser genérico, que representa a nossa essência humana. É na processualidade das relações sociais que o adolescente expressa a sua concepção de ser e de reproduzir o resultado de tudo o que apreendeu e tomou para si como significativo. Esse processo de confronto entre aquilo que é ensinado com o que é praticado efetivamente em sociedade se expressa pelas linguagens empreendidas pelo sujeito, e não acontecem de forma autônoma ${ }^{21}$.

${ }^{21}$ A partir do conceito etimológico para autonomia: 1. faculdade de se governar por si mesmo. 2. Faculdade de se reger por leis próprias (SANTOS, p. 74), entende-se que as estruturas sociais incidem sobre a linguagem dos sujeitos (e em suas formações discursivas) através das formações ideológicas, de forma a perpetrar valores do status quo. Por essa razão, ainda que o sujeito utilize a linguagem para expressar e comunicar o que pensa e sente essas construções na verdade ocorrem em um contexto macrossocial pré-estabelecido. Sendo assim ele se expressa através de sua linguagem em uma relação de resistência a tudo aquilo com que não tem identificação, mas ao mesmo tempo encontra-se reproduzindo linguagens (valores e sentidos) com as quais se identifica. Portanto, entende-se que a autonomia como conceito amplo constitui-se uma dimensão idealizada, ou melhor, possível de ser realizada somente em alguns aspectos, nunca totalmente alcançada, pois vai de encontro à própria condição do ser que vive sob regência de leis sociais. 
Em nosso tempo histórico os sujeitos vêm cada vez mais encontrando nos meios virtuais seu espaço preferencial para exercer sua comunicabilidade e socialização. É com as linguagens em suas diversas formas que as relações sociais vêm se constituindo em campo virtual impregnado pela lógica da sociedade do consumo. Os sujeitos hoje se deparam com os valores propostos por uma sociedade que defende interesses individuais reduzindo sujeitos a cidadãos consumidores. $\mathrm{O}$ estímulo a perceber e agir basicamente no sentido de satisfação de suas necessidades pessoais, porém essa prática precisa vir acompanhada do sentido de liberdade com posicionamento reflexivo com relação às ações, aos atos de si para si, de si para o outro. Foucault nos diz "o que é a ética senão a prática da liberdade, a prática refletida da liberdade?", pois entende que "a liberdade é a condição ontológica da ética. Mas a ética é a forma refletida assumida pela liberdade” (FOUCAULT, 2004, p. 267).

Partindo da concepção ontológica do ser, é perceptível que a atual realidade se apresente ao indivíduo, ainda mais contraditória, pois no meio virtual o adolescente conta com sofisticados recursos tecnológicos que o conectam com o mundo. As possibilidades que os meios virtuais oferecem ao sujeito uma condição de comunicabilidade e socialização do conhecimento nunca antes vivenciada historicamente. Frente a essa possibilidade de formação social em um meio que amplia os campos geográficos e de acesso atemporal do conhecimento e de abrangência do contato humano, entretanto é importante mencionar que, em determinadas situações não se apresentam claramente ao sujeito os limites que constituem o cuidado de si e do outro. Ocorre que a virtualidade introduz as práticas éticas em uma dimensão em que os sujeitos, onde não há parâmetros estabelecidos " $\mathrm{em}$ relação aos outros e para os outros” (FOUCAULT, 2004, p. 271).

Para Foucault o cuidado de si vem eticamente em primeiro lugar, antes do cuidado do outro. Na Internet essa afirmativa fica evidente na exposição a qual os adolescentes submetem a sua vida pessoal, muitas vezes não avaliando as consequências ao 
divulgarem sua intimidade. $\mathrm{O}$ adolescente adquire um poder, pois pode utilizar a linguagem em um meio onde essa se propaga sem limite de tempo ou espaço, ele torna-se imortal, pois coloca sua marca no mundo a um sem número de sujeitos, sem que necessariamente tenha de travar um relacionamento anteriormente. A processualidade se inverte, as barreiras formais do que pode ou deve ser dito deixam de existir, pois o sujeito possui em suas mãos o poder de exercer, na linguagem virtual, sem cerceamento de algo ou de alguém. Há uma nova maneira de ser, um campo virtual onde ele se identifica publicamente com suas características mais íntimas, divulgando seus pensamentos, sentimentos e seus significados para uma plateia que poderá identificar-se ou não, demonstrar afinidade ou rejeição.

Em sua essência, os valores humanos são transmitidos na relação com o outro, logo se pode dizer que os valores éticos balizados coletivamente estão cada vez mais esquecidos o que, por sua vez, compromete seriamente a formação social do adolescente. A construção de um ser ético, um ser que precisa se ver e se perceber como sujeito ético que faz parte de um todo não se dá sem a relação intrinsecamente humana. Um ser que coloca suas verdades na rede virtual na forma de frases, pequenos enunciados, procura exercer sua liberdade em seu cotidiano no movimento das linguagens virtuais, indo do particular ao universal, ainda que as determinações das relações de dominação/ subjugação o levem para a fragmentação do "nós", do conjunto. Um sujeito ético, crê-se, seria aquele capaz de ver em suas ações empreendidas circulando livremente em meio virtual, a formação de si como sujeito na relação com o outro, o encontro com o nós em meio virtual. Para Foucault, "tal estado de comunicação no qual os jogos de verdade poderiam circular sem obstáculos, sem restrições e sem efeitos coercitivos” (FOUCAULT, 2004, p. 284) parecem a ele de ordem utópica, porém, até certo ponto é exatamente o que constitui hoje o ambiente virtual.

A falta de parâmetro sobre o que pode ser exposto não impede a contribuição das linguagens virtuais para o adolescente. 
Ele é um sujeito em formação e essas linguagens são ferramentas que conferem a essa formação patamares ainda não devidamente reconhecidos. Seja pelos saberes dispostos, ou pelas habilidades cognitivas, psicomotoras e de desenvolvimento socioafetivo que estimula, tais aspectos necessitam de um importante referencial levantado por Outeiral $(2003,66)$, que é saber "que modelos para a identificação dos adolescentes oferece a sociedade brasileira? Quais são os valores éticos e morais que oferecemos aos jovens?”. Para Outeiral (2003) a sociedade brasileira, pelos meios de comunicação, nas atitudes de determinados setores políticos e empresariais, se oferecem atitudes éticas e valores que não podem ser considerados modelos de identificação positivos.

Interrelacionando os autores, compreende-se que uma comunicação sem barreiras atemporais e que integrem o adolescente a uma dimensão espacial ampla confere a ele uma mobilidade sociohistórica nunca antes vivenciada pelos sujeitos; há uma relativização do plano real, do que é passível de ser construído e realizado. Para Zagury, os adolescentes contemporâneos usufruem de condiçôes conquistadas anteriormente pelos pais, ocasionando um "alargamento da adolescência" (ZAGURY, 1996, p. 69), pois "dentro de suas casas eles tem uma liberdade e um espaço" que as gerações passadas não tiveram. Ou seja, o adolescente vive em seu cotidiano o tipo de comunicação que Foucault (2004) considerava utópica, sem restrições de tempo ou espaço, é sua realidade hoje tornar-se um ser atemporal e ampliado geograficamente.

Essa realidade experenciada no meio virtual coloca-o em contato permanente com o exercício de novas potencialidades e habilidades como sujeito social. Porém, para esse constituir-se como sujeito ético é preciso o vínculo com os sujeitos mais próximos a ele fisicamente, sujeitos presentes desde o início de sua vida em sociedade. Esses sujeitos que Outeiral e Zagury apontam como os transmissores essenciais dos modelos de identificação para "mostrar a realidade, as dificuldades, $[. .$.$] ouvir suas opiniốes,$ pedir que ajudem nas decisões também são formas importantes de fazê-los crescer e amadurecer” (ZAGURY, 1996, p. 73). 
As linguagens virtuais representam ferramentas que possibilitam o burilar das habilidades dos adolescentes e também, pelo contato com outros sujeitos praticado nesse meio, se realiza o exercício dos valores éticos. Para Aguiar \& Ozella (OZELLA, 2003 , p. 255),

[...] homem e sociedade vivem uma relação de mediação, em que um expressa e contém o outro, sem se diluírem, sem perderem sua singularidade $[. .$.$] internalizando e expressando sua condição histórica e social,$ a ideologia e as relações vividas.

É preciso nos deter com atenção a essa postura tão característica do adolescente, muitas vezes indevidamente compreendida; neste estudo a vemos sob o ponto de vista da ontologia, na perspectiva de que "se mexemos em, como vejo, o mundo e o saber, o mundo muda, eu mudo, o sentido que se dá à vida é alterado" (PELIZZOLI, 2006, p. 118). A ontologia, no sentido histórico, diz da própria formação sociohistórica do sujeito, e se falamos em valores buscando sua relação com a formação do ser como sujeito social, estamos falando da forma como ele "concebe o real, a matéria, o corpo humano", e desses sujeitos dentro das relações sociais.

A virtualidade da palavra confere novas configurações e uma nova dimensão sociohistórica, o meio virtual é hoje um espaço de mediação das relações sociais. Para o adolescente a virtualidade the traz uma vivência lúdica e imediata da vida cotidiana; através do texto e das imagens, ele se posiciona livremente, desafiando a si e ao meio social todos os conceitos repassados a ele pela sociedade. Uma nova postura contestatória e rebeldia ao que lhe é posto inicia-se na sua construção como ser ético, assim $\mathrm{o}$ adolescente revê as contradiçôes constantes no fazer humano daquilo que lhe é ensinado e o que é efetivamente praticado pelo mundo adulto. Ele constrói assim seus sentidos frente às significações sociais, construindo sua identidade como ser ético. 


\section{Considerações Finais}

A virtualidade é um espaço muitas vezes frequentado fisicamente de forma solitária. É o sujeito construindo sentidos nos enunciados que coloca virtualmente, não há e certamente não deve haver uma interferência externa do que ele pode ou deve inserir na Internet, são na verdade os valores éticos que precisam exercer esse diálogo com o sujeito.

Um dos atributos da essência humana é a liberdade, pensá-la em termos éticos remete à noção de responsabilidade naquilo que se posta no meio virtual. O conteúdo inserido na rede mundial passa a ser de domínio público, o comentário postado será visto por pessoas conhecidas, mas ele pode ser copiado e repassado a muitas outras pessoas e essa ação poderá atingir resultados imprevisíveis. A exposição de dados pessoais, fotos ou conteúdo que identifique o sujeito pode adquirir sentidos diversos que fogem do controle do adolescente. $\mathrm{O}$ acesso à vida privada até certa época era algo que necessitava da permissão do sujeito, na realidade virtualizada não é necessariamente o que ocorre. A ânsia de revelar-se a outro que se imagina com afinidades, o sujeito expõe sua intimidade de maneira tão explícita que demandaria a existência de um relacionamento anterior para justificar essa exposição.

As habilidades e capacidades despertas pelas linguagens virtuais trouxeram aos sujeitos uma nova forma de organização do conhecimento e de elaboração da escrita. São conceitos a serem observados cuidadosamente em razão da influência que a linguagem constitui para a formação do ser e, consequentemente, na compreensão dos valores éticos e sua aplicabilidade na sociedade. As habilidades elaboradas pelo próprio adolescente dentro do meio virtual revela a reunião de conhecimentos que, uma vez alicerçados com o apoio educacional qualificado, representa seminal contribuição em terreno fértil para a construção da autonomia que o levará ao posicionamento ético como sujeito social. 
O adolescente, na busca de autoafirmação, entra em confronto com as velhas formas de expressão, esse movimento natural é necessário para o desenvolvimento, pois ele encontra-se apreendendo a realidade em tempo virtual, ou seja, formas antigas de comunicação estão aquém do seu processo de compreender e se expressar. A rapidez das mudanças e novas linguagens não o assustam, pelo contrário, é o que o motiva a estar "ligado" naquilo que está sendo ofertado a ele. Essa nova condição constitui-se em habilidades que, se não forem devidamente compreendidas e potencializadas de forma positiva e emancipatória, serão analisadas e entendidas na sociedade como características de desrespeito nas demais relações fora do grupo adolescente.

É na sociedade, através do acesso aos direitos civis, econômicos e sociais que o adolescente ratifica sua posição na comunidade como ser pertencente. Pode-se dizer que a sociedade ao garantir seus direitos responsabiliza-se por ele. Porém na realidade concreta essa é uma lógica que não acontece para todos os jovens. Seu desenvolvimento como ser precisa do sentido do coletivo, posto que ao exercer seu papel de cidadão ele lute não pela garantia dos seus direitos civis, sociais e políticos, mas por toda a coletividade. É preciso trabalhar ativamente o conceito de cidadania com o adolescente, desatrelá-lo do "ter" enquanto posse de algo material para encontrar seu significado como ser humano.

\section{Referências}

ABREU, Marina Maciel. Serviço Social e a organização da cultura: perfis pedagógicos da prática profissional. São Paulo: Cortez, 2002.

ALMEIDA, Djanira Soares de Oliveira. Linguagem. In: MARCONI, Marina; PRESOTTO, Zélia (Orgs.). Antropologia: uma introdução. 5. ed. São Paulo: Atlas, 2001. (Cap. 15, p. 294).

ALVES, Rubem. Educação dos sentidos e mais... Campinas: Verus Editora, 2005. 
ARIÈS, Philippe. História Social da Criança e da Família. Rio de Janeiro: LTC, 1981.

BAKHTIN, Mikhail. Marxismo e filosofia da linguagem: problemas fundamentais do método sociológico na ciência da linguagem. São Paulo: Hucitec, 1992.

BENVENISTE, Émile. Problemas de linguística geral I. Campinas: Pontes/Editora Universidade Estadual de Campinas, 1991.

BUZZI, Arcângelo R. Introdução ao pensar: o ser, o conhecimento, a linguagem. Petrópolis: Vozes, 1990.

CABRAL, Edson Araújo et al. (Orgs.). Sistema de Garantia de Direitos: um caminho para a proteção integral. Centro Dom Helder Câmara de Estudos e Ação Social - CENDHEC, Recife: 1999. (Cadernos CENDHEC - Vol. 8)

CARVAJAL, Guilhermo. Tornar-se adolescente: a aventura de uma metamorfose: uma visão psicanalítica da adolescência. São Paulo: Cortez, 2001.

COSERIU, Eugenio. El Hombre y su Lenguaje. Madrid: Gredos, 1977.

DEMO, Pedro. Desafios modernos da educação. Rio de Janeiro: Vozes, 1993.

FIORIN, José Luiz. Linguagem e Ideologia. Série Princípios. São Paulo: Ática, 1993.

FOUCAULT, Michel. Em defesa da sociedade. Rio de Janeiro: Forense Universitária, 1999.

Ética, sexualidade, política. MOTTA, Manoel Barros da (Org. e Sel.). Tradução de Elisa Monteiro e Inês Autran Dourado Barbosa. Rio de Janeiro: Forense Universitária, 2004. (Coleção Ditos \& Escritos V).

GRAMSCI, Antonio. Concepção Dialética da História. Rio de Janeiro: Civilização Brasileira, 1995.

JULIA, Didier. Dicionário de filosofia. Rio de Janeiro: Editora Larousse do Brasil, 1969.

KOSIK, Karel. Dialética do Concreto. São Paulo: Paz e Terra, 2002. 
LAROUSSE, Grande Dicionário Larousse Cultural da Língua Portugue$s a$. Edição org. pela Ed. Nova Cultural, parcialmente derivada da Grande Enciclopédia Larousse Cultural, 1995. São Paulo: Nova Cultural, 1999.

MATURANA, Humberto. Emoções e linguagem na educação e na política. Belo Horizonte: Editora UFMG, 1998.

OUTEIRAL, José. Adolescer: estudos revisados sobre adolescência. Rio de Janeiro: Revinter, 2003.

OZELLA, Sergio (Org.) Adolescências construídas: a visão da psicologia sócio-histórica. São Paulo: Cortez, 2003.

PELIZZOLI, Marcelo. A bioética como novo paradigma e os limites do cartesianismo. In: PIZZI, Jovino; PIRES, Cecília (Orgs.). Desafios éticos e políticos da cidadania: ensaios de Ética e Filosofia Política II. Ijuí: Ed. Unijuí, 2006. (Coleção Filosofia v. 20).

SANTOS, Volnyr (Coord.). DELP: Dicionário Essencial da Língua Portuguesa. Porto Alegre: Rígel, 2006.

VILARREAL, Inga. Prólogo. In: CARVAJAL, Guilhermo. Tornar-se adolescente: a aventura de uma metamorfose: uma visão psicanalítica da adolescência. São Paulo: Cortez, p. 11, 2001.

ZAGURY, Tania. $O$ adolescente por ele mesmo. Rio de Janeiro: Record, 1996. 